\title{
POSSIBLE LINKS BETWEEN INTESTINAL PERMEABLITY AND FOOD PROCESSING: A POTENTIAL THERAPEUTIC NICHE FOR GLUTAMINE
}

\author{
Jean Robert Rapin,, ${ }^{\mathrm{IIII}}$ Nicolas Wiernsperger ${ }^{\mathrm{II}, \mathrm{III}}$
}

doi: $10.1590 / \mathbf{S 1 8 0 7 - 5 9 3 2 2 0 1 0 0 0 0 6 0 0 0 1 2}$

Rapin JR, Wiernsperger N. Possible links between intestinal permeablity and food processing: a potential therapeutic niche for glutamine. Clinics. 2010;65(6):635-43.

Increased intestinal permeability is a likely cause of various pathologies, such as allergies and metabolic or even cardiovascular disturbances. Intestinal permeability is found in many severe clinical situations and in common disorders such as irritable bowel syndrome. In these conditions, substances that are normally unable to cross the epithelial barrier gain access to the systemic circulation. To illustrate the potential harmfulness of leaky gut, we present an argument based on examples linked to protein or lipid glycation induced by modern food processing. Increased intestinal permeability should be largely improved by dietary addition of compounds, such as glutamine or curcumin, which both have the mechanistic potential to inhibit the inflammation and oxidative stress linked to tight junction opening. This brief review aims to increase physician awareness of this common, albeit largely unrecognized, pathology, which may be easily prevented or improved by means of simple nutritional changes.

KEYWORDS: Intestinal permeability; Glycation; Allergy; Metabolic syndrome; Glutamine; Curcumin.

\section{INTRODUCTION}

The intestinal wall represents a first-line, very efficient barrier for many potentially harmful alimentary or bacterial substances. ${ }^{1}$ Increased intestinal permeability (IP) is a common problem found in several diseases that directly affect the gut, including common conditions such as irritable bowel disease (IBD) and more severe diseases such as Crohn's disease, celiac diseases ${ }^{2,3}$ and other pathologies. ${ }^{4}$ Therefore, it is conceivable that substances that normally do not or only slightly cross the intestinal wall can exert pathological effects under such disease circumstances.

Food allergies ${ }^{5,6}$ and metabolic syndrome are common complaints in daily general practice, and the reported increases in the prevalence of these disorders may be associated with the abnormal passage of elements into the

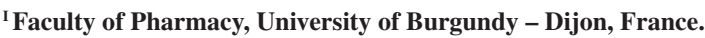

II INSERM - Villeurbanne, France.

III Association REMEDES - Orlienas, France.

Tel : 33 4723-10579

Email: jeanrobert.rapin@gmail.com

Received for publication on January 27, 2010

First review completed on February 17, 2010

Accepted for publication on March 04, 2010
}

general circulation. The present article will show supporting evidence for this hypothesis and suggest that natural inhibitors of IP, such as glutamine, may be useful for these disorders. However, severe clinical conditions will not be addressed herein. A role for the diet in modulating IP will be discussed. ${ }^{7}$ In view of the rising problem of modern food processing (solid aliments, beverages), ${ }^{8}$ we have selected glycated proteins and lipids as particularly relevant and interesting examples to illustrate how diet modulates IP.

\section{INTESTINAL BARRIER / INTESTINAL PERMEABILITY}

Prevention of the entrance of toxic or infectious molecules, such as solutes, antigens and microorganisms, is ensured by the gastrointestinal lining. A key structure of the intercellular space is the tight junction, which plays a major role in regulating the paracellular passage of luminal elements. ${ }^{9,10}$ Therefore, proper functioning and regulation of tight junctions is crucial. These junctions are under the influence of intestinal microflora, inflammation and even alimentary components, which can compromise tight junctions. Detailed information on the structures involved in tight junctions and their connections with the immediate 
anatomical environment can be found in dedicated reviews. ${ }^{11,12}$

Active debate has focused on the causal mechanisms of increased IP. This phenomenon may be directly due to local contact with luminal stimuli or may be secondary to increased transcellular transfer of antigens, thereby activating mast cells and disrupting tight junctions via inflammation. ${ }^{11,13,14}$ Cytokines such as TNF- $\alpha$ and various interleukins play a prominent role in tight junction disruption $^{15,16}$

Increased permeability (or "leaky gut") is typically observed in IBD, ${ }^{2,17,18}$ but it is also seen in various pathologies that are initially indirectly related to gut disorders, including inflammatory response syndrome, allergies, asthma and even autism. ${ }^{19}$ The autoimmune disorder type 1 diabetes may involve IP, ${ }^{20,21}$ whereas type 2 diabetes does not seem to present this disturbance. ${ }^{22}$ Infections or stress can also lead to perturbations of the intestinal barrier, meaning that initial structural defects of the barrier are not necessary to develop food allergies. ${ }^{23}$ Conversely, the presence of IP is not uniform among patients, although the majority of IBD patients and subjects with pseudoallergic reactions in chronic urticaria present IP. ${ }^{24}$ In patients with food intolerance, hyperpermeability was observed in approximately half of the studied population, ${ }^{25}$ whereas other investigators have reported a very high prevalence in patients with either food allergies or hypersensitivity. ${ }^{16}$ The reversibility of the defect is controversial, given that some data suggest that withdrawal of the food allergen for six months was not accompanied by IP improvements. ${ }^{16}$

Taken together, these data strongly support the hypothesis that in cases of elevated IP, the increased passage of substances that are normally largely or completely blocked by the intestinal barrier do gain systemic access. These substances may cause deleterious effects on health, producing allergies and metabolic and/or vascular changes.

\section{FOOD PROCESSING AND NON-ENZYMATIC GLYCATION}

\section{Glycation, AGEs and ALEs}

A normal diet contains relatively low levels of glycated proteins or lipids. Non-enzymatic glycation occurs in a series of conditions, the best known of which is elevated temperature. The combination of high temperatures in industrial food conservation, flavoring and daily home cooking with increased use of sugars has led researchers to investigate the content of advanced glycation end products (AGEs) and glycated lipids (ALEs) in modern food and to study their possible harmfulness. AGEs are the final product of a chain of reactions in which reducing sugars spontaneously react with aminopeptides, lipids and nucleic acids. This reaction initially creates so-called browning products (glycotoxins) due to the Maillard reaction. Amadori products are formed later in the reaction, and AGE is finally formed via recombination. The best-known AGEs are carboxymethyllysine (CML) and pentosidine, for which several measurement techniques have been developed based on their fluorescent nature. However, amino-containing lipids are also subjected to glycation and represent an important component of high-fat diets. Various chemical reactions during this process generate free radicals. ${ }^{26}$ Once formed, AGEs induce inflammation, ${ }^{27,28}$ which may further exacerbate IP. The formation of AGE/ALE is strongly accelerated by cooking in the moderate to high temperature range.

\section{Pharmacokinetics}

Normally, dietary AGEs cross the intestinal wall poorly; ${ }^{29,30} \mathrm{AGE}$ transport across the intestinal epithelium is low and occurs via simple diffusion. ${ }^{31}$ After intravenous administration, AGEs are largely eliminated by hepatic sinusoidal Kupffer and endothelial cells. ${ }^{32}$ However, elimination might be very different if IP is elevated and may be more threatening if renal function is also impaired, limiting urinary excretion of AGEs. Minimal data exist regarding the pharmacokinetics of AGEs, and data on absorption rate of glycated products are variable; pyrroline and pentosidine appear to be well absorbed, while peptidebound Amadori products are not. ${ }^{33}$ These varying findings may be due to the capacity of intestinal epithelial cells to degrade these various compounds. However, it should be noted that data exist only for some selected, measurable AGEs, while myriad different AGEs exist due to permanent recombination among AGEs. Consequently, the actual amount of AGEs absorbed may exceed the values obtained thus far.

\section{Glycation in food}

Comparison of different cooking methods has shown that identical substances can behave very differently. For example, strongly roasting typically increases allergenicity of peanuts.34 In addition, carboxymethyllysine content is significantly higher in infant formulas than in breast milk. ${ }^{35-}$ ${ }^{37}$ High-fat meals have the highest AGE content, more than meat and carbohydrate-rich meals. This also depends on the cooking method because broiling and frying generates more glycated compounds than roasting, and the least 
amount of glycated compounds is generated by boiling. ${ }^{38}$ Thus, the safest cooking method appears to be slow boiling at reasonable temperatures. Alpha-dicarbonyls (the most prone to form glycation), which are found naturally in green coffee, increase if beans are subjected to light or medium roasting, while dark roasted coffee contains fewer of these compounds. ${ }^{39}$ Therefore, very high temperatures during food processing denaturate proteins that have lower glycation capacity. Consequently, the recognition of epitopes by $\mathrm{IgE}$ is diminished. ${ }^{40,41}$ In parallel, protein digestibility is lower if the diet is rich in browning products. ${ }^{42}$ Glycation of food allergens increases T-cell immunogenicity of food allergens. ${ }^{43}$ Finally, postprandial leptin concentrations, which are lower in diabetics, improve if meals are heated with low temperatures. ${ }^{44}$

Recently, strong concerns were raised regarding increasing consumption of sweetened beverages. Researchers have begun to suspect a link between the high intake of reducing sugars and the incidence of metabolic dysregulation, such as metabolic syndrome, in younger populations. Sweetened fruit juices contain high levels of fructose, and levels are significantly greater than those found in whole, fresh fruits. ${ }^{45}$ Fructose is linked to metabolic syndrome, hyperlipidemia and type 2 diabetes. ${ }^{46}$ Methylglyoxal, a strong glycating agent, is also present in many beverages. ${ }^{47}$ Tea, coffee, diet coke and soy sauce have a high AGE content. In diabetic patients, fructose absorption is increased by prevailing hyperglycemia. In addition, kidney function is often compromised in these patients, which suggests that dietary AGEs add to those synthesized endogenously by the high glucose levels. ${ }^{30}$

\section{The impact of glycated products on health}

Increased passage of glycated compounds into the systemic circulation is expected to induce at least two pathological situations: allergies and metabolic disorders.

\section{Allergies}

Although only minimal data exit on AGEs and allergies, the existing data are consistent with our hypothesis. The induction of IP by tacrolimus leads to more food allergies. ${ }^{11,48}$ Exposure of intestinal $\mathrm{CaCO} 2$ cells to methylglyoxal or glyoxal, two potent glycating metabolites, in vitro is followed by increased IL- 6 and IL- 8 formation, which amplify the effects of TNF- $\alpha$ and IL- $1 \beta .{ }^{49}$ Some data suggest that AGEs may cause intestinal inflammation on their own. ${ }^{50}$ IL-9 has been reported to play a particularly important role in allergy by mediating the mast cell response. Indeed, IL-9 deficient mice do not develop anaphylaxis, whereas IL-9 overexpression does produce anaphylaxis. ${ }^{51}$ IL-17 has also been suggested to be important in food allergies. ${ }^{52}$ These inflammation signs have been confirmed in vivo. When dietary AGEs from casein form a complex with serum albumin, the receptor for AGE (RAGE) is stimulated and induces inflammation. ${ }^{27,53}$ RAGE is expressed in the intestinal epithelium and increases when interferon $\gamma$ or TNF- $\alpha$ are high, such as in IBD. ${ }^{54,55}$ Samples from IBD patients have confirmed that RAGE increases and that NF-B is activated. ${ }^{56}$ As a sign of allergenicity, IBD subjects were shown to have elevated $\mathrm{IgG}$ levels response to some foods, ${ }^{57}$ confirming the findings of various studies of gastrointestinal diseases in dogs. ${ }^{58}$ When compared with raw food antigens, IgE antibodies were elevated four-fold against processed food antigens in $30 \%$ of humans. ${ }^{59}$ The allergenicity of peanuts relates to their curing temperature $\left(77^{\circ} \mathrm{C}\right)$ and roasting. ${ }^{60}$ Similar findings have been reported for soybean-based products. ${ }^{61}$ Finally, AGEs can also modify the gut microbiota. ${ }^{62}$ Thus, although we could not find direct data on food allergy prevalence among patients with increased IP, this set of surrogate measurements strongly supports an association between food allergies and IP. ${ }^{63}$

\section{Metabolic disorders}

The recent recognition that dietary AGEs are absorbed and the fact that AGE consumption is constantly increasing in the westernized diet have prompted investigations on possible causal relationships between AGEs and observed metabolic disturbances. A first-line candidate for a link in the causal relationship is fructose, a relatively strong glycating sugar widely used in sweetened beverages and corn syrup. ${ }^{64}$ For example fructose consumption correlates with worldwide obesity and diabetes prevalence. Chronic intake of sweetened beverages increases triglycerides and ApoB concentrations in obese patients. ${ }^{65,66}$ Recently, a Brazilian study revealed that high intake of dietary fructose was associated with glucose intolerance. ${ }^{45}$ Approximately one-third of IBD patients present with fructose intolerance. ${ }^{67}$ In these subjects at least, fructose may have harmful effects. Fructose is lipogenic and can provoke non-alcoholic steatotic hepatitis (NASH). ${ }^{68}$ Whether normal levels of dietary fructose intake increase glycation in healthy subjects remains a matter of debate. ${ }^{69-71}$ One reason for the debate is that while fructose is more reactive than glucose in AGE formation, blood concentrations of fructose are low. ${ }^{72}$ When rats are fed a high-fructose diet, the AGE pentosidine accumulates in the aorta and skin. ${ }^{73}$ Similarly, comparison of different sugars in rats showed that glycation and oxidative stress occurred preferentially in fructose-fed animals. ${ }^{74}$ While it is not known whether humans handle dietary fructose like 
rodents, it should be stressed that chronic fructose-feeding, whether in pellets or in the drinking water, is one of the best experimental models to simulate metabolic syndrome and the evolution toward human diabetes. Recent studies have suggested that the diabetogenic effect of fructose occurs via increases in uric acid. ${ }^{46,75}$ Therefore, fructose consumption should be kept to a minimum..$^{76-78}$

A chronic diet including 1\% methylglyoxal induces insulin resistance and salt-sensitivity in Sprague-Dawley rats. ${ }^{79} \mathrm{~A}$ high-fat diet has also been shown to be a good model to simulate human metabolic syndrome. Accordingly, rodents chronically kept on high-fat diets exhibit insulin resistance, dyslipidemia and finally diabetes in a majority of animals within six months. ${ }^{80}$

As described above, high-fat diets contain high levels of AGEs and ALEs. Thus, high AGE and ALE levels may represent risk factors for human health by favoring inflammation in various organs, at least if subjects have compromised organ function. ${ }^{81}$ The processing of food to induce high AGE levels leads to adipocyte dysfunction, as shown by reduced leptin and adiponectin production as well as the increased oxidative stress. ${ }^{82}$ The autoimmune origin of type 1 diabetes has been linked to increased IP, and a prominent involvement of gliadin in IP activation, which can activate pancreatic $\mathrm{T}$ cells, has been proposed.. ${ }^{20}$ Gliadin stimulates zonulin signaling, leading to intestinal hyperpermeability. ${ }^{83}$ Very interestingly, type 2 diabetic patients were shown to have increased zonulin. ${ }^{84}$ Furthermore, in diabetic db/db mice, restricted intake of oral AGEs improved insulin sensitivity. ${ }^{85}$ Several mechanisms have been proposed to explain how AGEs lead to insulin resistance via the AGE receptor, ${ }^{86,87}$ but direct structural modifications of insulin itself by methylglyoxal have also been shown. ${ }^{88}$ The harmful association between nutrition, hyperglycemia and impaired renal function may relate to AGE intake in humans. ${ }^{89}$ Nevertheless, the causal implication of food-derived AGEs on these three outcomes is still debated and worthy of further investigation..$^{90,91}$ Two clinical studies are presently being conducted to more closely evaluate the impact of AGEs on human health. ${ }^{92,93}$

A high-fat diet increases visceral AGEs and promotes DNA fragmentation and apoptosis in the liver. ${ }^{94}$ Obese mice have NASH and increased IP, rendering hepatic stellate cells sensitive to bacterial endotoxins. ${ }^{95}$ Moreover, chronic liver diseases are linked to increased IP, ${ }^{96}$ which is important when considering that most prediabetic and diabetic patients have NASH.

\section{Other pathologies}

Lifespan was shown to be extended in mice fed low-
AGE diets, suggesting that AGEs are involved in aging. ${ }^{97,98}$ In addition, atopic dermatitis has been proposed to involve dietary antigens; however, this proposal remains a matter of debate. ${ }^{12}$ Furthermore, patients with ankylosing spondylitis and their relatives present with increased permeability in the small intestine, ${ }^{99}$ and Campylobacter infection increases IP, which can last up to one year postinfection. ${ }^{100}$

\section{Cardiovascular disturbances}

In certain rodent strains, fructose can lead to hypertension. For example, vascular reactivity in fructosefed animals showed a 35\% reduction in flow-mediated dilatation, ${ }^{82}$ and adhesion molecules were also increased, ${ }^{101}$ reflecting endothelial dysfunction. In diabetic patients, high AGE-containing meals are more harmful to microvascular function and oxidative stress than low-AGE food. ${ }^{102}$

\section{TREATMENTS}

As described above, strong support suggests that higher prevalence and severity of various diseases can be expected in the presence of intestinal hyperpermeability. Most of these diseases are chronic and can be treated by simple nutraceutical approaches. Consequently, improving IP may be a simple an inexpensive way to prevent aggravation of chronic diseases.

\section{Glutamine}

Glutamine is presently the best known compound for reducing IP, and nutritional depletion is known to result in increased IP. ${ }^{103-106}$ Major abnormalities in IP have been demonstrated in glutamine-deprived rat pups. ${ }^{107}$ Furthermore, glutamine has been shown to maintain transepithelial resistance and to reduce permeability in intestinal cell culture monolayers. ${ }^{108}$ In addition, glutamine supplementation has been shown to increase intestinal barrier function in malnourished children. ${ }^{109}$ However, glutamine has no effect if administered parenterally to depleted patients. ${ }^{110}$ Glutamine is the preferential substrate for enterocytes, and it works in concert with other amino acids, such as leucine and arginine, to maintain integrity and function. ${ }^{111}$ Several studies have demonstrated the beneficial effects of glutamine on IP. For example, improvements in the intestinal barrier have been shown in experimental biliary obstruction, ${ }^{112}$ after ischemia/reperfusion ${ }^{113}$ and even in severe clinical situations, such as in critically ill patients, in whom glutamine lowered the frequency of infections ${ }^{114}$ following abdominal surgery. ${ }^{115}$ Furthermore, in IBD treatment, the use glutamine alone or in combination with 
other amino acids is considered promising. ${ }^{116}$ In low birth weight children, allergies were improved by glutamine treatment during the first year of life. ${ }^{117}$ These non-nutritive effects of glutamine have recently been reviewed, ${ }^{118}$ and these effects have been ascribed to the antioxidant properties of glutamine and the enhanced expression of heat shock proteins. ${ }^{119}$

\section{Curcumin}

Curcumin (turmeric) has remarkable properties in inflammation and oxidative stress ${ }^{120,121}$ and is a potent immunomodulator. ${ }^{122}$ It is able to reduce acrylamide-induced injury in HepG2 cells. ${ }^{123}$ In addition, it partly inhibits the fibrogenic evolution and oxidative stress in the steatotic mouse liver in vivo. ${ }^{124}$ Curcumin has also been shown to be efficacious in experimental colitis ${ }^{125}$ as well as in colonic inflammation in multidrug-resistant mice, which exhibit IBD. ${ }^{126}$ Thus, curcumin might be a good candidate to treat $\mathrm{IBD}^{127}$ but it presents some theoretical limits. Indeed, like most antioxidants, curcumin should be used at moderate doses because at high doses it can enhance oxidative stress. ${ }^{128}$ Moreover, curcumin is rapidly cleared and conjugated, which may limit its therapeutic effectiveness as a single agent. ${ }^{129}$

Although the precise mechanisms of action of both compounds (in particular glutamine) must be further elucidated, an association between glutamine and curcumin is interesting in view of their complementary mechanistic properties, which correspond well to the pathological disturbances characterizing intestinal epithelial cell injury. We believe that testing the association between the two compounds would be clinically worthwhile.

\section{Other treatments}

Pre- and probiotics are also of potential interest. In obese and diabetic mice, which exhibit increased IP, prebiotic carbohydrates lowered IP and hepatic expression of markers of inflammation and oxidative stress. ${ }^{130}$ In humans, prebiotics reduced gut permeability in atopic dermatitis. ${ }^{131}$ In addition, probiotic carbohydrates lowered IP and inflammation in metabolic diseases. ${ }^{132,133} \mathrm{~A}$ mixture of streptococcus thermophilus and lactobacillus acidophilus protected the intestinal barrier in experimental colitis. ${ }^{134}$ Leaky gut was also improved by the probiotic Escherichia coli Nissle 1917. ${ }^{135}$ In addition, various substances have been tested and have been reported to have protective effects on IP; however, qualified studies on these substances are lacking. ${ }^{136-138}$ Overall, approaches using pre- and probiotics still need confirmatory investigations. ${ }^{139-141}$

\section{CONCLUSION}

Intestinal hyperpermeability is found in many diseases, from specific mild or severe gastrointestinal diseases to various pathologies linked to metabolic disorders. The abnormal transfer of pathogens from the intestinal lumen into the systemic circulation leads to disturbances in various organs, including the liver where it seems to be closely linked to non-alcoholic steatotic hepatitis. Allergies and vascular problems also appear to involve elevated IP. We have attempted to illustrate how alimentary compounds induced via modern cooking, food conservation and food processing methods may be associated with these pathologies when IP is increased. These associations are certainly largely unrecognized and not necessarily easy to identify. The aim of this overview was to increase scientist awareness of this simple idea and draw attention to what we believe is a very common clinical situation. Although still at the conceptual level, we feel that much supporting data can be found through the literature to suggest that early use of natural compounds, such as glutamine or curcumin (or a combination of both), and possible probiotics in the near future might represent a simple method to prevent the appearance or aggravation of many chronic pathologies.

\section{REFERENCES}

1. Farhadi A, Banan A, Fields J, Keshavarzian A. Intestinal barrier: an interface between health and disease. J Gastroenterol Hepatol. 2003;18:479-97.

2. Hollander D. Intestinal permeability, leaky gut, and intestinal disorders. Curr Gastroenterol Rep. 1999;1:410-6.

3. Camilleri M, Gorman H. Intestinal permeability and irritable bowel syndrome. Neurogastroenterol Motil. 2007;19:545-52.

4. DeMeo MT, Mutlu EA, Keshavarzian A, Tobin MC. Intestinal permeation and gastrointestinal disease. J Clin Gastroenterol. 2002;34:385-96.
5. Madsen C. Prevalence of food allergy: an overview. Proc Nutr Soc. 2005;64:413-7.

6. Rona RJ, Keil T, Summers C, Gislason D, Zuidmeer L, Sodergren E, et al. The prevalence of food allergy: a meta-analysis. J Allergy Clin Immunol. 2007;120:638-46.

7. Chapman-Kiddell CA, Davies PS, Gillen L, Radford-Smith GL. Role of diet in the development of inflammatory bowel disease. Inflamm Bowel Dis. 2010;16:137-51. 
8. Vlassara H. Advanced glycation in health and disease: role of the modern environment. Ann N Y Acad Sci. 2005;1043:452-60.

9. Gonzalez-Mariscal L, Tapia R, Chamorro D. Crosstalk of tight junction components with signaling pathways. Biochim Biophys Acta. 2008;1778:729-56.

10. Laukoetter MG, Nava P, Nusrat A. Role of the intestinal barrier in inflammatory bowel disease. World J Gastroenterol. 2008;14:401-7.

11. Groschwitz KR, Hogan SP. Intestinal barrier function: molecular regulation and disease pathogenesis. J Allergy Clin Immunol. 2009;124:3-20;quiz 1-2.

12. Arrieta MC, Bistritz L, Meddings JB. Alterations in intestinal permeability. Gut. $2006 ; 55: 1512-20$.

13. Edelblum KL, Turner JR. The tight junction in inflammatory disease: communication breakdown. Curr Opin Pharmacol. 2009;9:715-20.

14. Mankertz J, Schulzke JD. Altered permeability in inflammatory bowel disease: pathophysiology and clinical implications. Curr Opin Gastroenterol. 2007;23:379-83.

15. Watson AJ, Duckworth CA, Guan Y, Montrose MH. Mechanisms of epithelial cell shedding in the Mammalian intestine and maintenance of barrier function. Ann N Y Acad Sci. 2009;1165:135-42.

16. Ventura MT, Polimeno L, Amoruso AC, Gatti F, Annoscia E, Marinaro $\mathrm{M}$, et al. Intestinal permeability in patients with adverse reactions to food. Dig Liver Dis. 2006 ;38:732-6.

17. Liu Z, Li N, Neu J. Tight junctions, leaky intestines, and pediatric diseases. Acta Paediatr. 2005;94:386-93.

18. Clayburgh DR, Shen L, Turner JR. A porous defense: the leaky epithelial barrier in intestinal disease. Lab Invest. 2004;84:282-91.

19. Theoharides TC, Doyle R, Francis K, Conti P, Kalogeromitros D. Novel therapeutic targets for autism. Trends Pharmacol Sci. 2008;29:375-82.

20. Visser J, Rozing J, Sapone A, Lammers K, Fasano A. Tight junctions, intestinal permeability, and autoimmunity: celiac disease and type 1 diabetes paradigms. Ann N Y Acad Sci. 2009;1165:195-205.

21. Vaarala O. Leaking gut in type 1 diabetes. Curr Opin Gastroenterol. 2008;24:701-6.

22. Cani PD, Delzenne NM. Interplay between obesity and associated metabolic disorders: new insights into the gut microbiota. Curr Opin Pharmacol. 2009;9:737-43.

22. Secondulfo M, de Magistris L, Sapone A, Di Monda G, Esposito P, Carratu R. Intestinal permeability and diabetes mellitus type 2. Minerva Gastroenterol Dietol. 1999;45:187-92.

23. Heyman M. Gut barrier dysfunction in food allergy. Eur J Gastroenterol Hepatol. 2005 ; 17:1279-85.

24. Buhner S, Reese I, Kuehl F, Lochs H, Zuberbier T. Pseudoallergic reactions in chronic urticaria are associated with altered gastroduodenal permeability. Allergy. 2004;59:1118-23.

25. Bjarnason I, MacPherson A, Hollander D. Intestinal permeability: an overview. Gastroenterology. 1995;108:1566-81.

26. Vlassara H, Uribarri J. Glycoxidation and diabetic complications: modern lessons and a warning? Rev Endocr Metab Disord. 2004;5:1818 .
27. Uribarri J, Cai W, Sandu O, Peppa M, Goldberg T, Vlassara H. Dietderived advanced glycation end products are major contributors to the body's AGE pool and induce inflammation in healthy subjects. Ann N Y Acad Sci. 2005;1043:461-6.

28. Bengmark S. Advanced glycation and lipoxidation end products-amplifiers of inflammation: the role of food. JPEN J Parenter Enteral Nutr. 2007;31:430-40

29. Chuyen NV. Toxicity of the AGEs generated from the Maillard reaction: on the relationship of food-AGEs and biological-AGEs. Mol Nutr Food Res. 2006;50:1140-9.

29. Faist V, Erbersdobler HF. Metabolic transit and in vivo effects of melanoidins and precursor compounds deriving from the Maillard reaction. Ann Nutr Metab. 2001;45:1-12.

30. Koschinsky T, He CJ, Mitsuhashi T, Bucala R, Liu C, Buenting C, et al. Orally absorbed reactive glycation products (glycotoxins): an environmental risk factor in diabetic nephropathy. Proc Natl Acad Sci U S A. 1997;94:6474-9.

31. Grunwald S, Krause R, Bruch M, Henle T, Brandsch M. Transepithelial flux of early and advanced glycation compounds across Caco-2 cell monolayers and their interaction with intestinal amino acid and peptide transport systems. Br J Nutr. 2006;95:1221-8.

32. Smedsrod B, Melkko J, Araki N, Sano H, Horiuchi S. Advanced glycation end products are eliminated by scavenger-receptor-mediated endocytosis in hepatic sinusoidal Kupffer and endothelial cells. Biochem J. 1997;322 ( Pt 2):567-73.

33. Forster A, Kuhne Y, Henle T. Studies on absorption and elimination of dietary maillard reaction products. Ann NY Acad Sci. 2005;1043:474-81.

34. Maleki SJ, Chung SY, Champagne ET, Raufman JP. The effects of roasting on the allergenic properties of peanut proteins. J Allergy Clin Immunol. 2000;106:763-8.

35. Dittrich R, Hoffmann I, Stahl P, Muller A, Beckmann MW, Pischetsrieder M. Concentrations of Nepsilon-carboxymethyllysine in human breast milk, infant formulas, and urine of infants. J Agric Food Chem. 2006;54:6924-8

36. Elliott RB. Diabetes--a man made disease. Med Hypotheses. 2006;67:388-91.

37. Sebekova K, Saavedra G, Zumpe C, Somoza V, Klenovicsova K, Birlouez-Aragon I. Plasma concentration and urinary excretion of $\mathrm{N}$ epsilon-(carboxymethyl)lysine in breast milk- and formula-fed infants. Ann N Y Acad Sci. 2008;1126:177-80.

38. Goldberg T, Cai W, Peppa M, Dardaine V, Baliga BS, Uribarri J, et al. Advanced glycoxidation end products in commonly consumed foods. J Am Diet Assoc. 2004;104:1287-91.

39. Daglia M, Papetti A, Aceti C, Sordelli B, Spini V, Gazzani G. Isolation and determination of alpha-dicarbonyl compounds by RP-HPLC-DAD in green and roasted coffee. J Agric Food Chem. 2007;55:8877-82.

40. Gruber P, Vieths S, Wangorsch A, Nerkamp J, Hofmann T. Maillard reaction and enzymatic browning affect the allergenicity of Pru av 1, the major allergen from cherry (Prunus avium). J Agric Food Chem. 2004;52:4002-7.

41. Taheri-Kafrani A, Gaudin JC, Rabesona H, Nioi C, Agarwal D, Drouet $\mathrm{M}$, et al. Effects of heating and glycation of beta-lactoglobulin on its recognition by $\mathrm{IgE}$ of sera from cow milk allergy patients. J Agric Food Chem. 2009;57:4974-82. 
42. Seiquer I, Diaz-Alguacil J, Delgado-Andrade C, Lopez-Frias M, Munoz Hoyos A, Galdo G, et al. Diets rich in Maillard reaction products affect protein digestibility in adolescent males aged 11-14 y. Am J Clin Nutr. 2006;83:1082-8

43. Ilchmann A, Burgdorf S, Scheurer S, Waibler Z, Nagai R, Wellner A, et al. Glycation of a food allergen by the Maillard reaction enhances its T-cell immunogenicity: Role of macrophage scavenger receptor class A type I and II. J Allergy Clin Immunol. 2009 Oct 27.

44. Stirban A, Negrean M, Gotting C, Stratmann B, Gawlowski T, MuellerRoesel M, et al. Leptin decreases postprandially in people with type 2 diabetes, an effect reduced by the cooking method. Horm Metab Res. 2008;40:896-900.

45. Sartorelli DS, Franco LJ, Gimeno SG, Ferreira SR, Cardoso MA. Dietary fructose, fruits, fruit juices and glucose tolerance status in JapaneseBrazilians. Nutr Metab Cardiovasc Dis. 2009;19:77-83.

46. Johnson RJ, Perez-Pozo SE, Sautin YY, Manitius J, Sanchez-Lozada LG, et al. Hypothesis: could excessive fructose intake and uric acid cause type 2 diabetes? Endocr Rev. 2009;30:96-116.

47. Tan D, Wang Y, Lo CY, Sang S, Ho CT. Methylglyoxal: its presence in beverages and potential scavengers. Ann NY Acad Sci. 2008;1126:72-5.

48. Ozdemir O, Arrey-Mensah A, Sorensen RU. Development of multiple food allergies in children taking tacrolimus after heart and liver transplantation. Pediatr Transplant. 2006 ;10:380-3.

49. Kuntz S, Rudloff S, Ehl J, Bretzel RG, Kunz C. Food derived carbonyl compounds affect basal and stimulated secretion of interleukin- 6 and -8 in Caco-2 cells. Eur J Nutr. 2009 ;48:499-503.

50. Webster J, Wilke M, Stahl P, Kientsch-Engel R, Munch G. [Maillard reaction products in food as pro-inflammatory and pro-arteriosclerotic factors of degenerative diseases]. Z Gerontol Geriatr. 2005;38:347-53.

51. Forbes EE, Groschwitz K, Abonia JP, Brandt EB, Cohen E, Blanchard C, et al. IL-9- and mast cell-mediated intestinal permeability predisposes to oral antigen hypersensitivity. J Exp Med. 2008;205:897-913.

52. Perrier C, Thierry AC, Mercenier A, Corthésy B. Allergen-specific antibody and cytokine responses, mast cell reactivity and intestinal permeability upon oral challenge of sensitized and tolerized mice. Clin Exp Allergy. 2010 Jan;40:153-62.

53. Deo P, Glenn JV, Powell LA, Stitt AW, Ames JM. Upregulation of oxidative stress markers in human microvascular endothelial cells by complexes of serum albumin and digestion products of glycated casein. J Biochem Mol Toxicol. 2009;23:364-72.

54. Zen K, Chen CX, Chen YT, Wilton R, Liu Y. Receptor for advanced glycation endproducts mediates neutrophil migration across intestinal epithelium. J Immunol. 2007 15;178:2483-90.

55. Zill H, Bek S, Hofmann T, Huber J, Frank O, Lindenmeier M, et al. RAGE-mediated MAPK activation by food-derived AGE and non-AGE products. Biochem Biophys Res Commun. 2003;300:311-5.

56. Andrassy M, Igwe J, Autschbach F, Volz C, Remppis A, Neurath MF, et al. Posttranslationally modified proteins as mediators of sustained intestinal inflammation. Am J Pathol. 2006;169:1223-37.

57. Zuo XL, Li YQ, Li WJ, Guo YT, Lu XF, Li JM, et al. Alterations of food antigen-specific serum immunoglobulins $\mathrm{G}$ and $\mathrm{E}$ antibodies in patients with irritable bowel syndrome and functional dyspepsia. Clin Exp Allergy. 2007;37:823-30.
58. Foster AP, Knowles TG, Moore AH, Cousins PD, Day MJ, Hall EJ. Serum IgE and $\mathrm{IgG}$ responses to food antigens in normal and atopic dogs, and dogs with gastrointestinal disease. Vet Immunol Immunopathol. 2003;92:113-24.

59. Vojdani A. Detection of $\operatorname{IgE}, \operatorname{IgG}, \operatorname{IgA}$ and $\operatorname{IgM}$ antibodies against raw and processed food antigens. Nutr Metab (Lond). 2009;6:22.

61. Franck P, Moneret Vautrin DA, Dousset B, Kanny G, Nabet P, GuenardBilbaut $\mathrm{L}$, et al. The allergenicity of soybean-based products is modified by food technologies. Int Arch Allergy Immunol. 2002;128:212-9.

62. Tuohy KM, Hinton DJ, Davies SJ, Crabbe MJ, Gibson GR, Ames JM Metabolism of Maillard reaction products by the human gut microbiota-implications for health. Mol Nutr Food Res. 2006;50:847-57.

63. Thomas K, Herouet-Guicheney C, Ladics G, Bannon G, Cockburn A, Crevel R, et al. Evaluating the effect of food processing on the potential human allergenicity of novel proteins: international workshop report. Food Chem Toxicol. 2007;45:1116-22.

64. Stanhope KL, Havel PJ. Endocrine and metabolic effects of consuming beverages sweetened with fructose, glucose, sucrose, or high-fructose corn syrup. Am J Clin Nutr. 2008 ;88:1733S-7S.

65. Le KA, Ith M, Kreis R, Faeh D, Bortolotti M, Tran C, et al. Fructose overconsumption causes dyslipidemia and ectopic lipid deposition in healthy subjects with and without a family history of type 2 diabetes. Am J Clin Nutr. 2009;89:1760-5.

66. Swarbrick MM, Stanhope KL, Elliott SS, Graham JL, Krauss RM, Christiansen MP, et al. Consumption of fructose-sweetened beverages for 10 weeks increases postprandial triacylglycerol and apolipoprotein-B concentrations in overweight and obese women. Br J Nutr. 2008;100:947-52.

67. Choi YK, Kraft N, Zimmerman B, Jackson M, Rao SS. Fructose intolerance in IBS and utility of fructose-restricted diet. J Clin Gastroenterol. 2008;42:233-8.

68. Spruss A, Bergheim I. Dietary fructose and intestinal barrier: potential risk factor in the pathogenesis of nonalcoholic fatty liver disease. J Nutr Biochem. 2009 Sep;20(9):657-62.

69. Miller A, Adeli K. Dietary fructose and the metabolic syndrome. Curr Opin Gastroenterol. 2008;24:204-9.

70. Murphy SP. The state of the science on dietary sweeteners containing fructose: summary and issues to be resolved. J Nutr. 2009;139:1269S-70S

72. Schalkwijk CG, Stehouwer CD, van Hinsbergh VW. Fructose-mediated non-enzymatic glycation: sweet coupling or bad modification. Diabetes Metab Res Rev. 2004 Sep-;20:369-82.

73. Mikulikova K, Eckhardt A, Kunes J, Zicha J, Miksik I. Advanced glycation end-product pentosidine accumulates in various tissues of rats with high fructose intake. Physiol Res. 2008;57:89-94.

74. Levi B, Werman MJ. Long-term fructose consumption accelerates glycation and several age-related variables in male rats. J Nutr. 1998;128:1442-9.

75. Angelopoulos TJ, Lowndes J, Zukley L, Melanson KJ, Nguyen V, Huffman A, et al. The effect of high-fructose corn syrup consumption on triglycerides and uric acid. J Nutr. 2009;139:1242S-5S.

76. Bantle JP. Dietary fructose and metabolic syndrome and diabetes. J Nutr. 2009;139:1263S-8S. 
77. Bray GA. Soft drink consumption and obesity: it is all about fructose. Curr Opin Lipidol. 2009 Dec 2.

78. Duffey KJ, Popkin BM. High-fructose corn syrup: is this what's for dinner? Am J Clin Nutr. 2008;88:1722S-32S.

79. Guo Q, Mori T, Jiang Y, Hu C, Osaki Y, Yoneki Y, et al. Methylglyoxal contributes to the development of insulin resistance and salt sensitivity in Sprague-Dawley rats. J Hypertens. 2009;27:1664-71.

80. Sandu O, Song K, Cai W, Zheng F, Uribarri J, Vlassara H. Insulin resistance and type 2 diabetes in high-fat-fed mice are linked to high glycotoxin intake. Diabetes. 2005;54:2314-9.

81. Baynes JW. Dietary ALEs are a risk to human health--NOT! Mol Nutr Food Res. 2007;51(9):1102-6.

83. Drago S, El Asmar R, Di Pierro M, Grazia Clemente M, Tripathi A, Sapone A, et al. Gliadin, zonulin and gut permeability: Effects on celiac and non-celiac intestinal mucosa and intestinal cell lines. Scand J Gastroenterol. 2006;41:408-19.

84. Sapone A, de Magistris L, Pietzak M, Clemente MG, Tripathi A, Cucca F, et al. Zonulin upregulation is associated with increased gut permeability in subjects with type 1 diabetes and their relatives. Diabetes. 2006;55;1443-9.

85. Hofmann SM, Dong HJ, Li Z, Cai W, Altomonte J, Thung SN, et al. Improved insulin sensitivity is associated with restricted intake of dietary glycoxidation products in the $\mathrm{db} / \mathrm{db}$ mouse. Diabetes. 2002;51:2082-9.

86. Cassese A, Esposito I, Fiory F, Barbagallo AP, Paturzo F, Mirra P, et al. In skeletal muscle advanced glycation end products (AGEs) inhibit insulin action and induce the formation of multimolecular complexes including the receptor for AGEs. J Biol Chem. 2008 26;283:36088-99.

87. Unoki H, Yamagishi S. Advanced glycation end products and insulin resistance. Curr Pharm Des. 2008;14:987-9.

88. Jia X, Olson DJ, Ross AR, Wu L. Structural and functional changes in human insulin induced by methylglyoxal. Faseb J. 2006 ;20:1555-7.

89. Kankova K. Diabetic threesome (hyperglycaemia, renal function and nutrition) and advanced glycation end products: evidence for the multiple-hit agent? Proc Nutr Soc. 2008 ;67:60-74.

90. Ames JM. Evidence against dietary advanced glycation endproducts being a risk to human health. Mol Nutr Food Res. 2007;51:1085-90.

91. Chung SY, Butts CL, Maleki SJ, Champagne ET. Linking peanut allergenicity to the processes of maturation, curing, and roasting. J Agric Food Chem. 2003;51:4273-7.

92. Pouillart P, Mauprivez H, Ait-Ameur L, Cayzeele A, Lecerf JM, Tessier FJ, et al. Strategy for the study of the health impact of dietary Maillard products in clinical studies: the example of the ICARE clinical study on healthy adults. Ann N Y Acad Sci. 2008;1126:173-6.

93. Yamagishi S, Matsui T, Nakamura K. Possible link of food-derived advanced glycation end products (AGEs) to the development of diabetes. Med Hypotheses. $2008 ; 71: 876-8$.

94. Li SY, Liu Y, Sigmon VK, McCort A, Ren J. High-fat diet enhances visceral advanced glycation end products, nuclear O-Glc-Nac modification, p38 mitogen-activated protein kinase activation and apoptosis. Diabetes Obes Metab. 2005;7:448-54.

95. Brun P, Castagliuolo I, Di Leo V, Buda A, Pinzani M, Palu G, et al. Increased intestinal permeability in obese mice: new evidence in the pathogenesis of nonalcoholic steatohepatitis. Am J Physiol Gastrointest Liver Physiol. 2007;292:G518-25.

96. Cariello R, Federico A, Sapone A, Tuccillo C, Scialdone VR, Tiso A, et al. Intestinal permeability in patients with chronic liver diseases: It's relationship with the aetiology and the entity of liver damage. Dig Liver Dis. 2009 Jun 5.

97. Cai W, He JC, Zhu L, Chen X, Wallenstein S, Striker GE, et al. Reduced oxidant stress and extended lifespan in mice exposed to a low glycotoxin diet: association with increased AGER1 expression. Am J Pathol. 2007; 170:1893-902.

98. Cai W, He JC, Zhu L, Chen X, Zheng F, Striker GE, et al. Oral glycotoxins determine the effects of calorie restriction on oxidant stress, age-related diseases, and lifespan. Am J Pathol. 2008;173:327-36.

99. Vaile JH, Meddings JB, Yacyshyn BR, Russell AS, Maksymowych WP. Bowel permeability and CD45RO expression on circulating CD20+ $\mathrm{B}$ cells in patients with ankylosing spondylitis and their relatives. J Rheumatol. 1999;26:128-35.

100.Spiller RC, Jenkins D, Thornley JP, Hebden JM, Wright T, Skinner M, et al. Increased rectal mucosal enteroendocrine cells, T lymphocytes, and increased gut permeability following acute Campylobacter enteritis and in post-dysenteric irritable bowel syndrome. Gut. 2000;47:804-11.

101.Stirban A, Negrean M, Gotting C, Uribarri J, Gawlowski T, Stratmann $\mathrm{B}$, et al. Dietary advanced glycation endproducts and oxidative stress: in vivo effects on endothelial function and adipokines. Ann N Y Acad Sci. 2008;1126:276-9.

102.Negrean M, Stirban A, Stratmann B, Gawlowski T, Horstmann T, Gotting $\mathrm{C}$, et al. Effects of low- and high-advanced glycation endproduct meals on macro- and microvascular endothelial function and oxidative stress in patients with type 2 diabetes mellitus. Am J Clin Nutr. 2007;85:1236-43.

103.Li N, Neu J. Glutamine deprivation alters intestinal tight junctions via a PI3-K/Akt mediated pathway in Caco-2 cells. J Nutr. 2009;139:710-4.

104.Hulsewe KW, van der Hulst RW, van Acker BA, von Meyenfeldt MF, Soeters PB. Inflammation rather than nutritional depletion determines glutamine concentrations and intestinal permeability. Clin Nutr. 2004;23:1209-16.

105.Lucendo AJ, De Rezende LC. Importance of nutrition in inflammatory bowel disease. World J Gastroenterol. 2009;15:2081-8.

106.van der Hulst RR, von Meyenfeldt MF, van Kreel BK, Thunnissen FB, Brummer RJ, Arends JW, et al. Gut permeability, intestinal morphology, and nutritional depletion. Nutrition. 1998;14:1-6.

107.Potsic B, Holliday N, Lewis P, Samuelson D, DeMarco V, Neu J. Glutamine supplementation and deprivation: effect on artificially reared rat small intestinal morphology. Pediatr Res. 2002 Sep;52:430-6.

108.Li N, Lewis P, Samuelson D, Liboni K, Neu J. Glutamine regulates Caco-2 11 tight junction proteins. Am J Physiol Gastrointest Liver Physiol. 2004;287:G726-33.

109.Lima AA, Brito LF, Ribeiro HB, Martins MC, Lustosa AP, Rocha EM, et al. Intestinal barrier function and weight gain in malnourished children taking glutamine supplemented enteral formula. J Pediatr Gastroenterol Nutr. 2005;40:28-35.

110.Hulsewe KW, van Acker BA, Hameeteman W, van der Hulst RR, Vainas $\mathrm{T}$, Arends JW, et al. Does glutamine-enriched parenteral nutrition really affect intestinal morphology and gut permeability? Clin Nutr. 2004;23:1217-25. 
111.Marc Rhoads J, Wu G. Glutamine, arginine, and leucine signaling in the intestine. Amino Acids. 2009;37:111-22.

112. White JS. Misconceptions about high-fructose corn syrup: is it uniquely responsible for obesity, reactive dicarbonyl compounds, and advanced glycation endproducts? J Nutr. 2009;139:1219S-27S.

113.Kozar RA, Schultz SG, Bick RJ, Poindexter BJ, DeSoignie R, Moore FA. Enteral glutamine but not alanine maintains small bowel barrier function after ischemia/reperfusion injury in rats. Shock. 2004;21:433-7.

114.De-Souza DA, Greene LJ. Intestinal permeability and systemic infections in critically ill patients: effect of glutamine. Crit Care Med. 2005;33:1125-35.

115.Quan ZF, Yang C, Li N, Li JS. Effect of glutamine on change in early postoperative intestinal permeability and its relation to systemic inflammatory response. World J Gastroenterol. 2004;10:1992-4.

116.Coëffier M, Marion-Letellier R, Déchelotte P. Potential for amino acids supplementation during inflammatory bowel diseases. Inflamm Bowel Dis. 2010;16:518-24.

117.van den Berg A, van Zwol A, Moll HA, Fetter WP, van Elburg RM. Glutamine-enriched enteral nutrition in very low-birth-weight infants: effect on the incidence of allergic and infectious diseases in the first year of life. Arch Pediatr Adolesc Med. 2007;161:1095-101.

118.Roth E. Nonnutritive effects of glutamine. J Nutr. 2008;138:2025S-31S.

119.Wischmeyer PE. Glutamine: role in critical illness and ongoing clinical trials. Curr Opin Gastroenterol. 2008;24:190-7.

120.Aggarwal BB, Sung B. Pharmacological basis for the role of curcumin in chronic diseases: an age-old spice with modern targets. Trends Pharmacol Sci. 2009;30:85-94.

121.Ak T, Gulcin I. Antioxidant and radical scavenging properties of curcumin. Chem Biol Interact. 2008;174:27-37.

122.Jagetia GC, Aggarwal BB. «Spicing up» of the immune system by curcumin. J Clin Immunol. 2007;27:19-35.

123.Cao J, Liu Y, Jia L, Jiang LP, Geng CY, Yao XF, et al. Curcumin attenuates acrylamide-induced cytotoxicity and genotoxicity in HepG2 cells by ROS scavenging. J Agric Food Chem. 2008;56:12059-63.

124. Vizzutti F, Provenzano A, Galastri S, Milani S, Delogu W, Novo E, et al. Curcumin limits the fibrogenic evolution of experimental steatohepatitis. Lab Invest. 2010;90:104-15.

125.Camacho-Barquero L, Villegas I, Sanchez-Calvo JM, Talero E, SanchezFidalgo S, Motilva V, et al. Curcumin, a Curcuma longa constituent, acts on MAPK $\mathrm{p} 38$ pathway modulating COX-2 and iNOS expression in chronic experimental colitis. Int Immunopharmacol. 2007;7:333-42.

126.Nones K, Dommels YE, Martell S, Butts C, McNabb WC, Park ZA, et al. The effects of dietary curcumin and rutin on colonic inflammation and gene expression in multidrug resistance gene-deficient (mdr1a-/-) mice, a model of inflammatory bowel diseases. Br J Nutr. 2009;101:169-81.
127.Hanai H, Sugimoto K. Curcumin has bright prospects for the treatment of inflammatory bowel disease. Curr Pharm Des. 2009;15:2087-94.

128.Banerjee A, Kunwar A, Mishra B, Priyadarsini KI. Concentration dependent antioxidant/pro-oxidant activity of curcumin studies from AAPH induced hemolysis of RBCs. Chem Biol Interact. 2008;174:1349.

129.Jurenka JS. Anti-inflammatory properties of curcumin, a major constituent of Curcuma longa: a review of preclinical and clinical research. Altern Med Rev. 2009;14:141-53.

130.Cani PD, Delzenne NM. Interplay between obesity and associated metabolic disorders: new insights into the gut microbiota. Curr Opin Pharmacol. 2009;9:737-43.

131.Vanderhoof JA. Probiotics in allergy management. J Pediatr Gastroenterol Nutr. 2008;47 Suppl 2:S38-40.

132. Mennigen R, Bruewer M. Effect of probiotics on intestinal barrier function. Ann N Y Acad Sci. 2009;1165:183-9.

133.Strowski MZ, Wiedenmann B. Probiotic carbohydrates reduce intestinal permeability and inflammation in metabolic diseases. Gut. 2009;58:1044-5.

134.Resta-Lenert SC, Barrett KE. Modulation of intestinal barrier properties by probiotics: role in reversing colitis. Ann N Y Acad Sci. 2009;1165:175-82.

135.Ukena SN, Singh A, Dringenberg U, Engelhardt R, Seidler U, Hansen W, et al. Probiotic Escherichia coli Nissle 1917 inhibits leaky gut by enhancing mucosal integrity. PLoS One. 2007;2:e1308.

136.Amasheh M, Andres S, Amasheh S, Fromm M, Schulzke JD. Barrier effects of nutritional factors. Ann N Y Acad Sci. 2009;1165:267-73.

137.Heizer WD, Southern S, McGovern S. The role of diet in symptoms of irritable bowel syndrome in adults: a narrative review. J Am Diet Assoc. 2009;109:1204-14.

137.White JS, Hoper M, Parks RW, Clements WD, Diamond T. Glutamine improves intestinal barrier function in experimental biliary obstruction. Eur Surg Res. 2005;37:342-7.

138. Shen YH, Nahas R. Complementary and alternative medicine for treatment of irritable bowel syndrome. Can Fam Physician. 2009;55:1438 .

139. Calder PC, Albers R, Antoine JM, Blum S, Bourdet-Sicard R, Ferns GA, et al. Inflammatory disease processes and interactions with nutrition. $\mathrm{Br}$ J Nutr. 2009 May;101 Suppl 1:S1-45.

140.Hartman C, Eliakim R, Shamir R. Nutritional status and nutritional therapy in inflammatory bowel diseases. World J Gastroenterol. 2009;15:2570-8.

141. O'Sullivan M, O'Morain C. Nutrition in inflammatory bowel disease. Best Pract Res Clin Gastroenterol. 2006;20:561-73. 